\title{
Resistências e imaginações conceituais em disputa
}

DOI

http://DX.DOI.ORG/ 10.11606/1678-9857 RA. 2020.189685

\section{Pedro de Niemeyer Cesarino}

Universidade de São Paulo, Faculdade de Filosofia, Letras e Ciências Humanas, Departamento de Antropologia, São Paulo, SP, Brasil

pncesarino@usp.br

ORCID: https://orcid.org/0000-0002-4158-7712

\section{Heloísa Buarque de Almeida}

Universidade de São Paulo, Faculdade de Filosofia, Letras e Ciências Humanas, Departamento de Antropologia, São Paulo, SP, Brasil

hbuarque@usp.br

ORCID: https://orcid.org/0000-0001-8126-5884

\section{Laura Moutinho}

Universidade de São Paulo, Faculdade de Filosofia, Letras e Ciências Humanas, Departamento de Antropologia, São Paulo, SP, Brasil

Imoutinho@usp.br

ORCID: https://orcid.org/0000-0001-6479-2711

\section{Júlio Assis Simões}

Universidade de São Paulo, Faculdade de Filosofia, Letras e Ciências Humanas, Departamento de Antropologia, São Paulo, SP, Brasil

juliosimoes@usp.br

ORCID: https://orcid.org/0000-0002-9000-3621

\author{
Renato Sztutman \\ Universidade de São Paulo, Faculdade de Filosofia, Letras \\ e Ciências Humanas, Departamento de Antropologia, São \\ Paulo, SP, Brasil \\ rsztutman@usp.br \\ ORCID: https://orcid.org/0000-0003-3871-4984
}

O número 64.3 da Revista de Antropologia contempla artigos de áreas diversas da disciplina que, contudo, são atravessados por tentativas de construir modos de pensamento, de existência e de resistência capazes de confrontar políticas e conceitos dominantes. Na realidade, a maneira pela qual tal confronto é realizado na disciplina está também em processo de intensa transformação, haja vista a reivindicação crescente pela participação de pesquisadorxs e pela formulação de proposições analíticas que não se enquadrem na hegemonia branca ocidentalizada característica não apenas da formação da antropologia mas, mais amplamente, da própria academia como um todo. Neste sentido, as transformações do conhecimento antropológico só fazem reagir (e espera-se que com contundência) às demandas de uma sociedade em plena ebulição, que já não mais aceita a condição de subalternidade imposta a grupos sociais e seus respectivos modos de existência. A disposição antirracista deve, portanto, coincidir com a própria vocação antropológica, ou então condená-la definitivamente à obsolescência.

Não por acaso, Alexandra Eliza Vieira Alencar, em "Re-existências: notas de uma antropóloga negra em meio a concursos públicos para o cargo de magistério superior", vai tratar da urgente necessidade de superação das desigualdades no ensino superior 
perpetradas pelo racismo institucional, através da análise da trajetória da própria autora em concursos públicos realizados em universidades federais. Num contexto em que 52,9\% do corpo docente (de universidades públicas e privadas) é branco, 14,4 $\%$ pardo e $2 \%$ preto, o desafio de superação do racismo e do machismo acaba por ser ainda mais vasto do que o envolvido nas (certamente fundamentais) políticas de ação afirmativa. Afinal, como bem aponta a autora, trata-se também de realizar uma profunda "mudança epistêmica nos currículos e práticas de formação acadêmica", ainda marcados pelo conhecimento ocidental, branco e masculino, também ele tributário da relação perversa entre genocídio e epistemicídio que devemos superar.

Luiza Dias Flores, em "A ocupação kilombola: "receita de resistência" do Território de Mãe Preta (RS)", não poderia estar mais sintonizada com tal tarefa. Seu estudo versa sobre a noção de ocupação desenvolvida pelos membros da comunidade kilombola Morada da Paz (RS). Aparentemente distinta daquelas relacionadas ao processo político associado, por exemplo, ao Movimento Sem Terra (MST), a noção e o processo de ocupação aí se desenvolvem a partir de uma comunidade espiritual e de uma "guerra cósmica". São elas as responsáveis por movimentar o processo de "retomada" da terra e de "reativação" de modos de existência perseguidos pela empresa colonial, em consonância com as reativações do animismo discutidas por pensadoras contemporâneas como Isabelle Stengers. Ao tratar das curas populares no Recôncavo da Bahia à luz do conceito de "configuração agentiva" cunhado por Perig Pitrou, Francesca Bassi, Fátima Tavares e Sílvia Michele Macedo de Sá em "Terapeutas populares no Recôncavo da Bahia, Brasil: configurações agentivas em ontologias híbridas", também se dedicam ao estudo de "agências ontologicamente híbridas" envolvidas nas relações entre humanos e não-humanos. Para as autoras, as práticas rituais do Recôncavo não se compreendem via a separação moderna entre esferas ontológicas e devem, antes, ser compreendidas pela existência de um único ambiente, de acordo com a acepção de Tim Ingold.

Em "O santo e o encantado: a procissão afro umbandista para São Sebastião em São João de Pirabas", Hermes de Sousa Veras apresenta um estudo etnográfico sobre uma procissão afro religiosa que envolve as figuras complexas de São Sebastião e de Rei Sabá, este último um encantado proteiforme de identidade fluida associado a orixás e a um antigo vodunsi. Marca fundamental do espaço urbano e da vida ritual coletiva, as entidades envolvidas em tal procissão atentam mais uma vez para modos de existência que escapam às reificações metropolitanas e seu enquadramento pela noção de manifestação cultural, mobilizada pela Igreja Católica como estratégia para preservar o seu monopólio da religião. Os pressupostos de pensamento que fundamentam tal monopólio, contudo, são mais uma vez abalados pela proposta ousada de Juliano Florczak Almeida que, em "Nem instituição, nem indivíduo: notas sobre carisma e agência a partir de testemunhos de graças de devotos de dois frades franciscanos", se dedica a discutir as noções de carisma e de agência entre devotos de santos católicos via a aproximação com os conceitos de divíduo e de distribuição da 
agência, originalmente elaborados a partir da etnologia melanesianista. Com isso, o artigo contribui para a transformação de estudos antropológicos sobre o cristianismo à luz de contribuições teóricas que lhes seriam estranhas à primeira vista, embora consigam se demonstrar capazes de conferir ganhos analíticos e de revelar processos obscurecidos pela abordagem sociológica tradicional do catolicismo.

Camila Galan de Paula, em "Assimetria e saliência: a relação entre iniciador/a e imitadores/as na circulação de bens industrializados entre os Wajãpi no Amapá”, dedicase ao estudo da circulação de mercadorias industrializadas entre os Wajãpi na tentativa de compreender as relações de simetria e de assimetria mobilizadas pelas noções de "imitação" e de "preconceito" retraduzidas por categorias locais. Na tentativa de não tomar relações sociais e econômicas capitalistas pelas ameríndias, a autora pretende tratar da difícil questão envolvida em "compreender acepções de imitar, preconceito, desigualdade que não estejam ancoradas em pressupostos da propriedade, do controle, da hierarquia, da produção". A reinvenção de processos provenientes do mundo não indígena é também assunto do artigo de Carlos Eduardo Costa, "Futebol em campo, no campo da etnologia: o desporto bretão e a esportividade ameríndia". Com foco no Alto Xingu, o autor procura tratar do futebol a partir da indagação sobre as esportividades ameríndias e a pluralização práticas corporais de origem ocidental. A redefinição do futebol por tais povos, termina por se envolver em relações de competitividade e de controle da violência que caracterizam dinâmicas intra e interétnicas desde sempre existentes, marcadas pela guerra e pela disputa.

No que se refere ao contexto urbano, Camila Fernandes, em "Casas de "tomar conta" e creches públicas: relações de cuidados e interdependência entre periferias e Estado", procura analisar, através de pesquisa conduzida no complexo do São Carlos, Zona Norte da cidade do Rio de Janeiro, as relações entre creches públicas e moradoras que trabalham como cuidadoras de crianças em favelas. $\mathrm{O}$ artigo aponta, assim, para a situação de subalternidade de mulheres periféricas envolvidas no "tomar conta" de crianças, em condição de precariedade e de desigualdade crônicas. O artigo "Formas de governo e complementaridade entre a administração estatal e seus administrados: reflexões a partir de um serviço para homens autores de violência doméstica", de Paulo Victor Leite Lopes, pretende, por sua vez, realizar uma "investigação acerca de processos de formação de Estado" via o estudo etnográfico de uma instância administrativa de acompanhamento de homens autores de violência doméstica. Para Lopes, tal investigação permite concluir que "essas técnicas de gestão são eficazes não apenas por (re)produzir formas de subjetivação e sujeição dos diretamente envolvidos, mas também podem ser revelar eficazes na manutenção cotidiana da crença (e do desejo) de Estado".

Tais enquadramentos, contudo, são frequentemente desafiados por práticas esportivas que produzem linhas de fuga para as intenções administrativas e capitalistas. O estudo "Os enquadramentos da citadinidade: sobre os impactos da prática do skate de rua na cidade de São Paulo", de Giancarlo Marques Carraro Machado, trata justamente 
da presença do skate na cidade de São Paulo como uma forma de desterritorialização do espaço urbano marcado pelo planejamento e pelo mercado. Em uma espécie de recusa teimosa, o skate termina por produzir, via Michel de Certeau, uma "redefinição do espaço como um lugar praticado com a apregoação de novas leituras e valores simbólicos". Natânia Lopes, em "Sentidos e fantasias sobre o "luxo" na prostituição de "alto escalão" carioca", debruça-se por fim sobre o universo da prostituição de luxo na cidade do Rio de Janeiro, ainda muito pouco estudado. Ao refletir sobre a própria categoria "luxo", a autora se depara com um campo semântico definido a partir de relações de poder clivadas pela hegemonia masculina heteronormativa: "Quem empresta o qualificativo "luxo" a estes meios e às próprias garotas são, portanto, os homens. É o pertencimento socioeconômico deles que define o luxo na prostituição de luxo." Mais uma vez, trata-se de demonstrar, via o rigor etnográfico e conceitual, que a história e origem de categorias e formas de pensamento dominantes não podem ser universalizadas ou naturalizadas, mas antes problematizadas à luz da reflexão antropológica e de seus compromissos políticos.

Neste número, a Revista de Antropologia abre uma nova seção intitulada "Experiências de Inclusão". Como se sabe, a Universidade de São Paulo chegou atrasada na implementação de políticas de ações afirmativas. Ainda assim vêm acontecendo iniciativas de diferentes ordens que visam promover a inclusão social e democratizar o acesso e a permanência de estudantes na instituição nos âmbitos da graduação e pósgraduação. Na Faculdade de Filosofia, Letras e Ciências Humanas (FFLCH), o Programa de Pós-Graduação em Antropologia (PPCAS) foi o primeiro Programa, há cinco anos, a incorporar reserva de vagas para indígenas e cotas para pretos/pardos, pessoas com deficiência e, desde 2021, pessoas trans (travestis, transexuais e transgêneros)' Portanto, algumas iniciativas vêm ocorrendo em distintas frentes. A proposta da nova seção é, justamente, abrir espaço para que essas experiências sejam registradas e partilhadas com um público mais amplo, de modo a ampliar o debate sobre o tema. Esta é, parece-nos, uma questão urgente, especialmente no momento em que se aproxima a data da revisão da Lei de Cotas nas Universidades, prevista para 2022.

Iniciaremos a nova seção com a publicação do artigo "Ensino de Antropologia em inglês: reflexões sobre uma experiência de inclusão", que aborda um projeto-piloto voltado ao letramento de discentes em língua inglesa, realizado em duas disciplinas obrigatórias de antropologia. $\mathrm{O}$ artigo de autoria de Laura Moutinho, Thais Tiriba e Rodrigo Brusco (2021) aborda debates contemporâneos nas áreas de Ciências Sociais e Letras que discutem a questão da inclusão e do letramento acadêmico, menciona experiência internacional na temática, compartilha a metodologia utilizada, reproduzindo atividades oferecidas e realiza ao final um balanço de toda a experiência pedagógica. A Revista de Antropologia, antenada com seu tempo, espera, dessa forma que essa e outras experiências vindouras contribuam para a discussão e reprodução de iniciativas voltadas para a inclusão social e democratização do acesso à universidade. 
Pedro de Niemeyer Cesarino é professor doutor do Departamento de Antropologia da FFLCH/USP e editor-chefe da Revista de Antropologia. Pulicou Oniska - poética do xamanismo na Amazônia (Ed. Perspectiva/FAPESP, 2011), Quando a Terra deixou de falar cantos da mitologia marubo (Ed. 34, 2013), entre outros livros e artigos.

Heloisa Buarque de Almeida é professora doutora no Departamento de Antropologia e no PPGAS-USP, e membro do NUMAS - Núcleo de Estudos dos Marcadores Sociais da Diferença. Foi Visiting Fellow na London School of Economics com bolsa FAPESP, é e membro do Conselho Científico da Associação Brasileira de Antropologia. É bolsista de produtividade do CNPq, e tem apoio da FAPESP.

Laura Moutinho é professora Associada (Livre-Docente) do Departamento de Antropologia e do PPCAS ambos da USP. Pesquisadora do NUMAS/USP. Coordena a Comissão Projeto Editorial da ABA. Publicou o livro Razão, Cor e Desejo: uma análise dos relacionamentos afetivo-sexuais inter-raciais no Brasil e África do Sul, Editora Unesp: São Paulo, 2004, graças ao prêmio EDUSC|ANPOCS para melhor tese de doutoradol edição 2003. É bolsista produtividade do CNPq e tem apoio da FAPESP.

Júlio Assis Simões é professor do Departamento de Antropologia e do Programa de Pós-Craduação em Antropologia Social da USP. É pesquisador líder do NUMAS - Núcleo de Estudos dos Marcadores Sociais da Diferença e bolsista de produtividade do CNPq.

Renato Sztutman é professor do Departamento de Antropologia e do Programa de Pós-Graduação em Antropologia Social (PPGAS) da Universidade de São Paulo. É bolsista produtividade do CNPq. Autor do livro O profeta e o principal: a ação política ameríndia e seus personagens (Edusp/ Fapesp,2012).

\section{REFERÊNCIAS BIBLIOGRÁFICAS}

ALENCAR, Alexandra Eliza Vieira. 2021.

"Re-existências: notas de uma antropóloga negra em meio a concursos públicos para o cargo de magistério superior". Revista de Antropologia, 64(3): e189647. http://dx.doi. org/10.11606/1678-9857.ra.2020.189647

ALMEIDA, Juliano Florczak. 2021.

"Nem instituição, nem indivíduo: notas sobre carisma e agência a partir de testemunhos de graças de devotos de dois frades franciscanos". Revista de Antropologia, 64(3): e189654. http://dx.doi. org/10.11606/1678-9857.ra.2020.189654

BASSI, Francesca; TAVARES, Fátima; SÁ, Sílvia Michele Macedo de. 2021. "Terapeutas populares no Recôncavo da Bahia, Brasil: configurações agentivas em ontologias híbridas". Revista de 
Antropologia, 64(3): e189651. http://dx.doi. org/10.11606/1678-9857.ra.2020.189651

COSTA, Carlos Eduardo. 2021. "Futebol em campo, no campo da etnologia: o desporto bretão e a esportividade ameríndia". Revista de Antropologia, 64(3): e189722. http://dx.doi. org/10.11606/1678-9857.ra.2020.189722

DE FIORI, Ana Letícia; ASSÊNSIO, Cibele Barbalho; ANDRADE, Fabiana, TEIXEIRA, Jacqueline Moraes, PATRIARCA, Letizia \& DAL BO, Talita Larazin. 2017. O tempo e o vento: notas sobre a arte de burocratizar políticas de cotas na USP. Revista de Antropologia, 60(1), 55-83. https://doi. org/10.11606/2179-0892.ra.2017.132101

FERNANDES, Camila. 2021. "Casas de "tomar conta" e creches públicas: relações de cuidados e interdependência entre periferias e Estado". Revista de Antropologia, 64(3): e189648. http://dx.doi. org/10.11606/1678-9857.ra.2020.189648

FLORES, Luiza Dias. 2021. "A ocupação kilombola: 'receita de resistência' do Território de Mãe Preta (RS)". Revista de Antropologia, 64(3): e189655. http://dx.doi. org/10.11606/1678-9857.ra.2020.189655

LOPES, Natânia. 2021. "Sentidos e fantasias sobre o "luxo" na prostituição de "alto escalão" carioca". Revista de Antropologia, 64(3): e189656. http://dx.doi. org/10.11606/1678-9857.ra.2020.189656
LOPES, Paulo Victor Leite. 2021. "Formas de governo e complementaridade entre a administração estatal e seus administrados: reflexões a partir de um serviço para homens autores de violência doméstica". Revista de Antropologia, 64(3): e189657. http://dx.doi. org/10.11606/1678-9857.ra.2020.189657

MACHADO, Giancarlo Marques Carraro. 2021. "Os enquadramentos da citadinidade: sobre os impactos da prática do skate de rua na cidade de São Paulo". Revista de Antropologia, 64(3): e189652. http://dx.doi. org/10.11606/1678-9857.ra.2020.189652

MOUTINHO, Laura, TIRIBA, Thais, \& BRUSCO, Rodrigo. 2021. Ensino de Antropologia em inglês: reflexões sobre uma experiência de inclusão. Revista de Antropologia, 64(3). https:// doi.org/10.11606/1678-9857.ra.2020.191370

PAULA, Camila Galan de. 2021. "Assimetria e saliência: a relação entre iniciador/a e imitadores/as na circulação de bens industrializados entre os Wajãpi no Amapá". Revista de Antropologia, 64(3): e189649. http:// dx.doi.org/10.11606/1678-9857.ra.2020.189649

VERAS, Hermes de Sousa. 2021. "O santo e o encantado: a procissão afro umbandista para São Sebastião em São João de Pirabas". Revista de Antropologia, 64(3): e189653. http:// dx.doi.org/10.11606/1678-9857.ra.2020.189653 